Marquette University

e-Publications@Marquette

Biomedical Engineering Faculty Research and

Publications

Biomedical Engineering, Department of

4-2013

\title{
Separation of Visual and Motor Workspaces During Targeted Reaching Results in Limited Generalization of Visuomotor Adaptation
}

Yuming Lei

University of Wisconsin - Milwaukee

Michelle J. Johnson

Marquette University, michelle.j.johnson@marquette.edu

Jinsung Wang

University of Wisconsin - Milwaukee

Follow this and additional works at: https://epublications.marquette.edu/bioengin_fac

Part of the Biomedical Engineering and Bioengineering Commons

\section{Recommended Citation}

Lei, Yuming; Johnson, Michelle J.; and Wang, Jinsung, "Separation of Visual and Motor Workspaces

During Targeted Reaching Results in Limited Generalization of Visuomotor Adaptation" (2013).

Biomedical Engineering Faculty Research and Publications. 343.

https://epublications.marquette.edu/bioengin_fac/343 


\title{
Separation of Visual and Motor Workspaces During Targeted Reaching Results in Limited Generalization of Visuomotor Adaptation
}

\author{
Yuming Lei \\ Department of Kinesiology, University of Wisconsin \\ Milwaukee, WI \\ Department of Biomedical Engineering, Marquette University \\ Milwaukee, WI \\ Michelle J. Johnson \\ Department of Biomedical Engineering, Marquette University \\ Milwaukee, WI \\ Department of Physical Medicine and Rehabilitation, Medical \\ College of Wisconsin \\ Milwaukee, WI \\ Jinsung Wang \\ Department of Kinesiology, University of Wisconsin \\ Milwaukee, WI
}

\begin{abstract}
:
Separating visual and proprioceptive information in terms of workspace locations during reaching movement has been shown to disturb transfer of visuomotor adaptation across the arms. Here, we investigated whether separating visual and motor workspaces would also disturb generalization of visuomotor adaptation across movement conditions within the same arm. Subjects were divided into four experimental groups (plus three control groups). The first two groups adapted to a visual rotation under a "dissociation" condition in which the targets for reaching movement were
\end{abstract}

Neuroscience Letters, Vol. 541 (April 2013): pg. 243-247. DOI. This article is (C Elsevier and permission has been granted for this version to appear in e-Publications@Marquette. Elsevier does not grant permission for this article to be further copied/distributed or hosted elsewhere without the express permission from Elsevier. 
NOT THE PUBLISHED VERSION; this is the author's final, peer-reviewed manuscript. The published version may be accessed by following the link in the citation at the bottom of the page.

presented in midline while their arm performed reaching movement laterally. Following that, they were tested in an "association" condition in which the visual and motor workspaces were combined in midline or laterally. The other two groups first adapted to the rotation in one association condition (medial or lateral), then were tested in the other association condition. The latter groups demonstrated complete transfer from the training to the generalization session, whereas the former groups demonstrated substantially limited transfer. These findings suggest that when visual and motor workspaces are separated, two internal models (vision-based one, proprioception-based one) are formed, and that a conflict between the two disrupts the development of an overall representation that underlies adaptation to a novel visuomotor transform.

Keywords: Vision; Proprioception; Transfer; Human; Motor learning

\section{Introduction}

Remapping of a relationship between visual and proprioceptive senses in the nervous system occurs when individuals adapt, for example, to a rotated visual display during targeted-reaching movement. To understand the nature of such visuomotor adaptations, various types of experimental paradigms have been used, one of which involves examining the influence that workspaces have on the pattern of visuomotor adaptation and its generalization [4], [7], [13], [14], [16], [18] and [19]. Some studies demonstrated extensive generalization of visuomotor adaptation across different workspaces, indicating that visuomotor remapping is not restricted to the workspace in which adaptation took place [4], [7], [14] and [16]. Other studies, however, demonstrated that individuals can adapt to conflicting visuomotor conditions simultaneously when the conditions are associated with different workspaces [13] and [18], suggesting that visuomotor remapping associated with a given condition can be localized to a specific workspace in which adaptation occurred. Given the two sets of findings that seemingly contradict each other, more research is needed to better understand the effect of workspaces on the pattern of visuomotor adaptation and its generalization.

In the aforementioned studies, generalization of visuomotor adaptation was examined across workspaces in which the same arm performed reaching movement. The effect of workspaces has also been examined in interlimb transfer studies, in which the workspaces where the two arms performed motor tasks were either combined or

Neuroscience Letters, Vol. 541 (April 2013): pg. 243-247. DOI. This article is (c) Elsevier and permission has been granted for this version to appear in e-Publications@Marquette. Elsevier does not grant permission for this article to be further copied/distributed or hosted elsewhere without the express permission from Elsevier. 
separated [8] and [17]. Sainburg and Wang [8] had subjects adapt to a rotated visual display with the dominant arm first, then with the nondominant arm, or vice versa, and observed that directional information of reaching movement only transferred from the nondominant to dominant arm. In that study, both arms adapted to the rotation in a shared midline workspace. In a follow-up study in which each arm adapted to the same rotation in a separate lateral workspace [17], directional information transferred in both directions (i.e., dominant to nondominant arm, and vice versa), indicating that the pattern of interlimb transfer depends on the workspace locations in which the arms adapt to visual rotations.

More recently, Wang [15] showed that interlimb transfer of directional information did not occur at all when visual and motor workspaces were separated during visuomotor adaptation (e.g., targets were displayed in a shared midline workspace while each arm physically performed the task in its ipsilateral workspace). This finding may indicate that a conflict between visual and proprioceptive information in terms of workspace locations inhibits the access of each arm controller to the movement information obtained by its counterpart, probably due to uncertainties in determining hand dominance at a given workspace. Alternatively, such a conflict may lead to incomplete development of a neural representation associated with the given visuomotor condition. These two interpretations lead to different predictions: the former predicts that a conflict between visual and motor workspaces should not interfere with generalization of visuomotor adaptation across movement conditions in which the same arm is used, whereas the latter predicts that it should. In the latter case, generalization across the arms should be minimal as well, because the neural representation developed during the initial training phase was incomplete in the first place. In the present study, thus, we separated visual and motor workspaces during visuomotor adaptation and examined how the adaptation would generalize across different conditions that involve the same arm movement.

\section{Materials and methods}

\subsection{Subjects}

Subjects were 35 healthy young adults (18-30 old, righthanded). Subjects were paid for their participation. Informed consent

Neuroscience Letters, Vol. 541 (April 2013): pg. 243-247. DOI. This article is (C) Elsevier and permission has been granted for this version to appear in e-Publications@Marquette. Elsevier does not grant permission for this article to be further copied/distributed or hosted elsewhere without the express permission from Elsevier. 
NOT THE PUBLISHED VERSION; this is the author's final, peer-reviewed manuscript. The published version may be accessed by following the link in the citation at the bottom of the page.

approved by the Institutional Review Board of the University of Wisconsin - Milwaukee was solicited prior to participation. Subjects were randomly assigned to one of seven groups ( 5 subjects per group).

\subsection{Apparatus}

A robotic exoskeleton called KINARM (BKIN Technologies Ltd, Kingston, ON, Canada) was used to collect data. Subjects were seated on a chair facing a table with the right arm supported on an exoskeleton. The KINARM was incorporated with a virtual reality system that projected visual targets on a horizontal display to make them appear in the same plane as the arm. Direct vision of the arm was blocked; and a cursor representing the index fingertip was provided to guide their reaching movement. The position of arm segments was sampled at $1000 \mathrm{~Hz}$, low-pass filtered at $15 \mathrm{~Hz}$, and differentiated to yield resultant velocity values. Data were processed and analyzed using MATLAB.

\subsection{Experimental design}

In general, subjects performed a rapid reaching movement made from a start circle to one of eight targets $(2 \mathrm{~cm}$ in diameter, $10 \mathrm{~cm}$ away from the start circle) presented in a pseudo-random sequence on a horizontal tabletop (Fig. 1). The start and target locations were fixed, which caused the joint angles to vary across the subjects. They were instructed to move their index finger to the target as straight as possible, and stop on it. The target appeared as the cursor representing the index fingertip was brought inside the start circle and remained visible for $2 \mathrm{~s}$. Movement onset and offset were defined by the last minimum (below $5 \%$ max. tangential velocity) prior to, and the first minimum following, the maximum in the tangential hand velocity profile, respectively. The experiment consisted of three sessions: baseline, training, and generalization sessions (96, 192, and 192 trials, respectively). In the baseline session, the subjects were familiarized with the general reaching movement; in the training and generalization sessions, they adapted to a visual display that was rotated 30 degrees counterclockwise about the start circle (e.g., hand movement made in the "12 O'clock" direction resulted in cursor movement made in the "11 O'clock" direction).

Neuroscience Letters, Vol. 541 (April 2013): pg. 243-247. DOI. This article is (C Elsevier and permission has been granted for this version to appear in e-Publications@Marquette. Elsevier does not grant permission for this article to be further copied/distributed or hosted elsewhere without the express permission from Elsevier. 
NOT THE PUBLISHED VERSION; this is the author's final, peer-reviewed manuscript. The published version may be accessed by following the link in the citation at the bottom of the page.

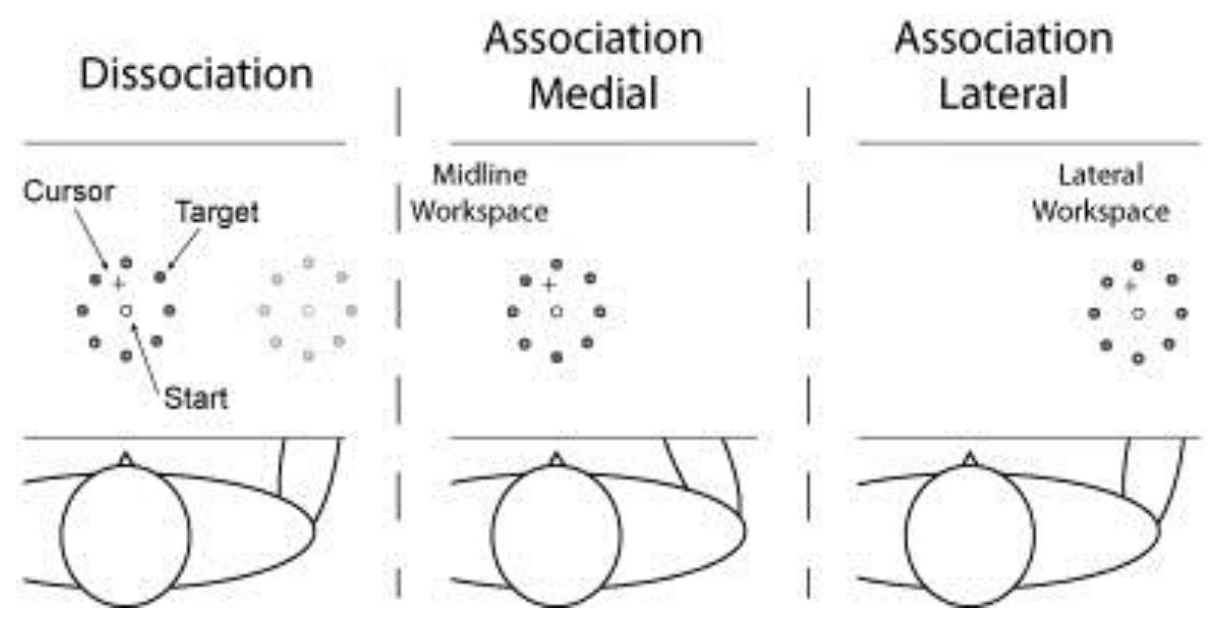

Fig. 1. Midline workspace was placed in front of the subject's torso. Lateral workspace was placed in front of the subject's right shoulder $(40 \mathrm{~cm}$ between midline and lateral workspace start circles). In dissociation condition, visual and motor workspaces were physically separated (gray circles shown on the right side were not visible to subjects). In association conditions, both visual and motor workspaces were presented in midline or laterally.

During the training and generalization sessions, the subjects performed the adaptation task in one of three experimental conditions: dissociation, association medial, and association lateral. In the dissociation (Dissoc) condition, visual and motor workspaces were separated in such a way that the cursor and the targets were presented in midline, while the subjects physically performed the adaptation task laterally (Fig. 1, left). The distance between the two start circles was $40 \mathrm{~cm}$. In the association medial (AssocM) condition, the cursor and the targets were presented in midline, and the subjects performed the task in the same midline workspace (Fig. 1, middle). In the association lateral (AssocL) condition, both the visual and the motor workspaces were presented laterally (Fig. 1, right).

To examine transfer of visuomotor adaptation from one workspace to another, subjects were divided into four experimental groups (Table 1). Those in groups 1 and 2 adapted to the rotated display under the dissociation condition in the training session. Following that, they performed the same adaptation task under one of the two association conditions in the generalization session. Those in groups 3 and 4 adapted to the rotation under one of the two association conditions in the training session, then under the other association condition in the generalization session. Additional subjects

Neuroscience Letters, Vol. 541 (April 2013): pg. 243-247. DOI. This article is (C) Elsevier and permission has been granted for this version to appear in e-Publications@Marquette. Elsevier does not grant permission for this article to be further copied/distributed or hosted elsewhere without the express permission from Elsevier. 
were tested in three control groups: they experienced the same experimental condition in both the training and the generalization sessions (groups 5-7).

Table 1. Subject groups and experimental conditions.

\begin{tabular}{|c|c|c|}
\hline \multirow{2}{*}{ Group ( $n=5$ per group) } & \multicolumn{2}{|l|}{ Session } \\
\hline & $\begin{array}{l}\text { Training }\left(30^{\circ} \text { rotation, } 192\right. \\
\text { trials })\end{array}$ & $\begin{array}{l}\text { Generalization ( } 30^{\circ} \text { rotation, } 192 \\
\text { trials) }\end{array}$ \\
\hline 1. Dissoc-to-AssocM & Dissociation & Association medial \\
\hline 2. Dissoc-to-AssocL & Dissociation & Association lateral \\
\hline 3. AssocM-to-AssocL & Association medial & Association lateral \\
\hline 4. AssocL-to-AssocM & Association lateral & Association medial \\
\hline 5. Dissoc-to-Dissoc (control) & Dissociation & Dissociation \\
\hline $\begin{array}{l}\text { 6. AssocM-to-AssocM } \\
\text { (control) }\end{array}$ & Association medial & Association medial \\
\hline $\begin{array}{l}\text { 7. AssocL-to-AssocL } \\
\text { (control) }\end{array}$ & Association lateral & Association lateral \\
\hline
\end{tabular}

\subsection{Data analysis}

Direction error (DE) was calculated as our main performance measure, which was the angular difference between a vector defined by the start and the target positions and another vector defined by the hand-path positions at movement start and at peak arm velocity.

For statistical analysis, data from the training and generalization sessions were subjected to two separate repeated-measures ANOVAs, which were conducted to examine the main effects of, and the interaction effect between, group and cycle (i.e., mean of eight consecutive trials), with the latter variable as a within-subject factor. Following that, paired $t$-tests were conducted between cycle 1 of the training session and cycle 1 of the generalization session, and also between the mean of last six cycles from the training session and cycle 1 of the generalization session to determine whether there was a significant transfer (in experimental subject groups), or retention of learning (in control subject groups), from the training to the generalization session within each group. In addition, we computed the percentage of transfer in each group by using the following equation: [(DE at cycle 1 of training session - DE at cycle 1 of generalization session)/(DE at cycle 1 of training session - DE at cycle

Neuroscience Letters, Vol. 541 (April 2013): pg. 243-247. DOI. This article is (C Elsevier and permission has been granted for this version to appear in e-Publications@Marquette. Elsevier does not grant permission for this article to be further copied/distributed or hosted elsewhere without the express permission from Elsevier 
24 of training session) $] \times 100(\%)$. These percentage scores from the seven subject groups were subjected to a one-way ANOVA; and post hoc, independent t-tests were conducted between the subject groups.

We also examined whether having the visual or motor workspace consistent across the two sessions would affect the course of learning in group 1 (consistent visual workspace) and group 2 (consistent motor workspace) differentially during the generalization session. A line of approximation was constructed for each subject in the two groups by finding a nonlinear logarithmic regression line; and the intercept and the slope of the regression equations obtained from each subject were subjected to independent $t$-tests. The alpha level was set at 0.05 for all statistical significance.

\section{Results}

Fig. 2 shows typical hand-paths of our representative subjects during the initial and final phases of the training session, and during the initial phase of the generalization session. These hand-paths are only shown for four subject groups (groups 1, 2, 3, 5): the hand-paths were very similar between groups 3 and 4 , and among groups 5-7.

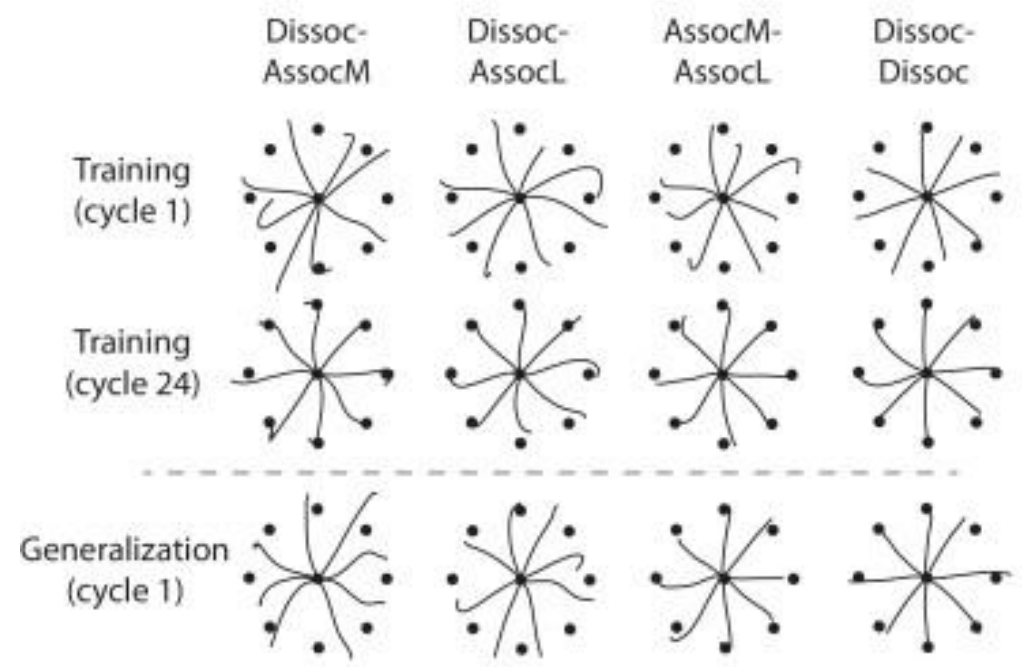

Fig. 2. Hand-paths from representative subjects. Each column shows hand-paths for four subject groups. Each row shows hand-paths of 8 consecutive trials of reaching movement made in 8 different target directions. Rows 1 and 3 show performances during the initial phase (cycle 1) of training and generalization sessions, respectively.

Neuroscience Letters, Vol. 541 (April 2013): pg. 243-247. DOI. This article is (C) Elsevier and permission has been granted for this version to appear in e-Publications@Marquette. Elsevier does not grant permission for this article to be further copied/distributed or hosted elsewhere without the express permission from Elsevier. 
Row 2 shows performances following complete adaptation to visuomotor rotations at the end of training session (cycle 24).

The hand-paths observed during the first cycle of the training session are substantially deviated from the target directions in every group (Fig. 2, row 1), indicating the influence of the visuomotor rotation. The hand-paths in all subject groups became relatively straight and accurate by the last cycle (row 2), indicating substantial visuomotor adaptation. During the generalization session, however, the performance appears to differ across the groups (row 3). The hand-paths observed at the first cycle of the generalization session were largely curved and inaccurate in the Dissoc-to-AssocM and the Dissoc-to-AssocL groups, indicating limited transfer of visuomotor adaptation from the training to the generalization session. In contrast, the hand-paths of all the other groups (including the groups not shown in Fig. 2) were relatively straight and accurate, indicating substantial transfer.

These data indicate that the extent of generalization was smaller in the subject groups who were trained in the dissociation condition and tested in the association conditions, which is confirmed by our performance measures shown in Fig. 3. The patterns of adaptation during the training and generalization sessions are only shown for the subject groups whose hand-path data were shown in Fig. 2 (groups 1, 2, 3 and 5). The adaptation patterns were very similar between groups 3 and 4, and among groups 5-7.

Neuroscience Letters, Vol. 541 (April 2013): pg. 243-247. DOI. This article is (C Elsevier and permission has been granted for this version to appear in e-Publications@Marquette. Elsevier does not grant permission for this article to be further copied/distributed or hosted elsewhere without the express permission from Elsevier. 
NOT THE PUBLISHED VERSION; this is the author's final, peer-reviewed manuscript. The published version may be accessed by following the link in the citation at the bottom of the page.
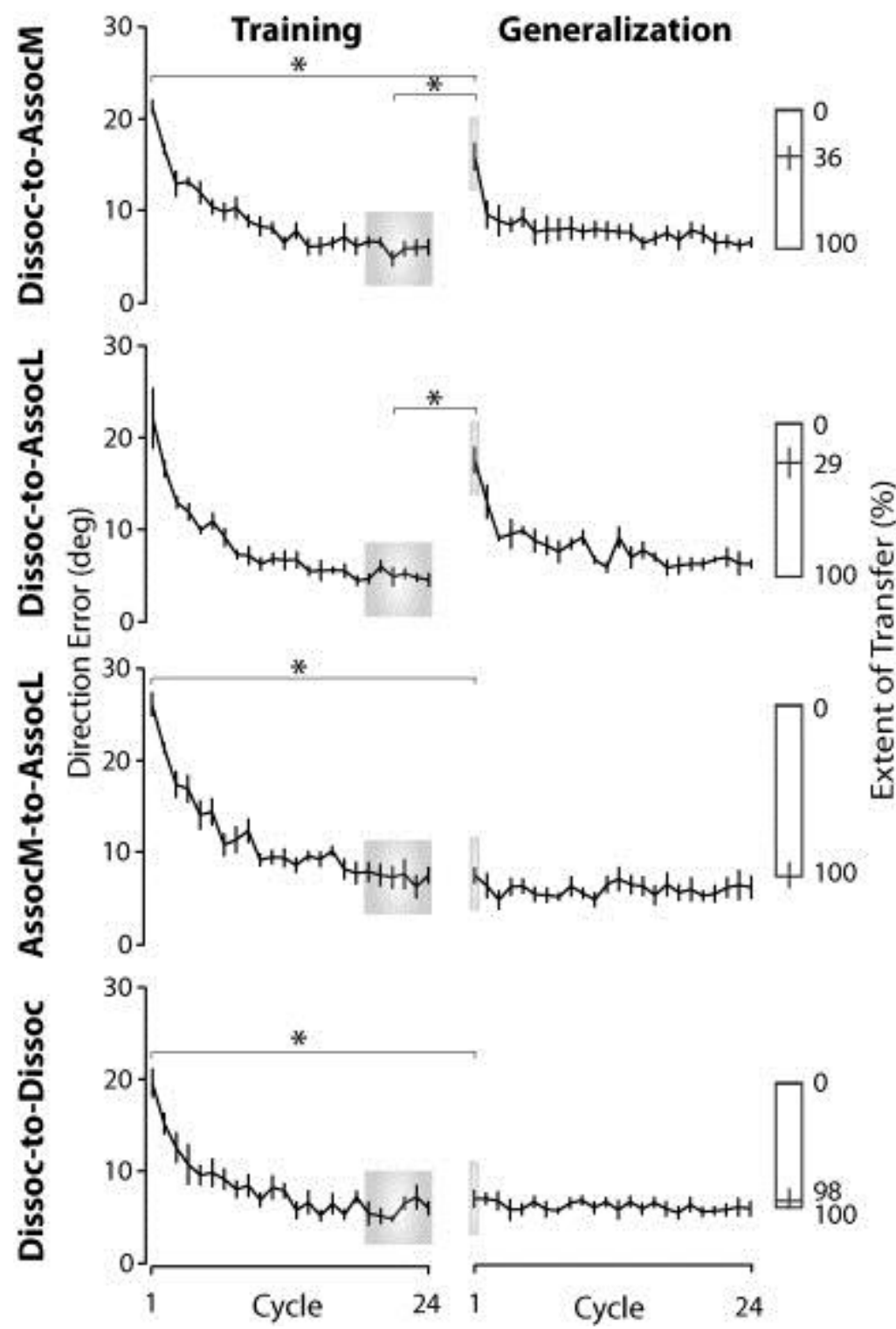

Fig. 3. Mean performance measures of DE. Every data point shown on $X$ axis of line graphs represents the mean $( \pm \mathrm{SE})$ of 8 consecutive trials (cycle) across all subjects. * indicates that comparisons between mean of cycle 1 , or last 6 cycles, from training session and mean of cycle 1 from generalization session are significantly different $(P<.05)$. Top and bottom of vertical bars indicate mean DE at cycle 1 and cycles 19-24 from training session; horizontal line inside the bars indicate DE ( \pm SE) at cycle 1 from generalization session, reflecting extent of transfer (\%).

With respect to DE (Fig. 3), our repeated-measures ANOVA indicated a significant main effect for cycle $(P<.05)$, but not for group, in the training session. No interaction effect was observed, either. In the generalization session, however, a significant interaction 
effect between group and cycle was observed $(P<.05)$, mainly due to the fact that the patterns of adaptation across the cycles observed in the Dissoc-to-AssocM and the Dissoc-to-AssocL groups were very different from those observed in all the other groups. The paired $t$ tests between the first cycles of the training and generalization sessions indicated a significant difference in every group except the Dissoc-to-AssocL group, in which the lack of significance was due to larger variability caused by one subject. Those between the mean of the last six cycles of the training session and the first cycle of the generalization session indicated a significant difference in the Dissocto-AssocM and the Dissoc-to-AssocL groups $(P<.01)$, while the two values were not significantly different in all the other groups. The oneway ANOVA using the percentage scores also indicated a significant difference across the subject groups $(P<.01)$. The post hoc tests revealed that the two dissociation groups, which were not different from each other, were significantly different from the association groups, which were not different from each other.

With regard to the course of learning in the Dissoc-to-AssocM and the Dissoc-to-AssocL groups during the generalization session, the rate of adaptation appeared somewhat faster in the Dissoc-to-AssocM group than in the other group, although the independent t-tests indicated that neither the intercept nor the slope of the regression equations was significantly different between the two subject groups. The regression equations for the Dissoc-to-AssocM and Dissoc-toAssocL groups were $Y=12.37-1.91 \ln (X)$ and $Y=14.69-2.81 \ln (X)$, respectively.

\section{Discussion}

In this study, we examined the effect of separating visual and motor workspaces during targeted-reaching movement on generalization of visuomotor adaptation across different workspace conditions in which the same arm was used. When the subjects first adapted to a visual rotation under a condition in which the visual and motor workspaces were combined, complete generalization occurred from the medial to lateral workspace, or vice versa. This is consistent with previous findings, which demonstrated extensive generalization of visuomotor adaptation across different workspaces [4], [7], [14] and [16]. When the subjects first adapted to the rotation under a condition in which the visual and motor workspaces were separated,

Neuroscience Letters, Vol. 541 (April 2013): pg. 243-247. DOI. This article is @ Elsevier and permission has been granted for this version to appear in e-Publications@Marquette. Elsevier does not grant permission for this article to be further copied/distributed or hosted elsewhere without the express permission from Elsevier. 
however, the extent of generalization was much smaller than that observed in the aforementioned condition. This finding indicates that the separation of visual and motor workspaces has a substantial influence on the pattern of generalization. The pattern of adaptation during the training session was not different between the two conditions, which is consistent with our previous findings [8] and [15].

We have previously demonstrated that the pattern of interlimb transfer depends on the workspace locations in which the two arms perform visuomotor tasks. We observed asymmetrical transfer of movement information (e.g., directional information transferring from nondominant to dominant arm, not vice versa) when both arms adapted to a visual rotation in a shared midline workspace [8], but symmetrical transfer (e.g., directional information transferring in both directions) when each arm adapted in its ipsilateral workspace [17]. This suggests that when visuomotor tasks are performed in workspaces that are not shared by the arms, both arm controllers have symmetrical access to the information acquired by the opposite arm controller. When the tasks are performed within a shared workspace, however, a certain competition may occur between the arm controllers, which selectively inhibits each controller from accessing the information for which the other controller is specialized, thus resulting in asymmetrical transfer. Other studies suggested that the dominant and nondominant limb/hemisphere systems are differentially specialized for controlling directional and positional features of movement, respectively [1] and [2]. This idea of selective inhibitions between the arm controllers was inspired by the findings reported by Gazzaniga and colleagues [3] and [5], which indicated that cognitive and motor processes that take place in each brain hemisphere can interfere with each other when the processes involve incompatible sets of information.

The pattern of interlimb transfer is influenced even more when visual and motor workspaces are separated: interlimb transfer does not occur at all when each arm performs visuomotor tasks in its ipsilateral workspace while the visual display is presented in midline, or vice versa [15]. The lack of interlimb transfer in that situation may indicate that a conflict between visual and motor workspaces inhibits each arm controller from accessing the movement information obtained by its counterpart, because of uncertainties in determining

Neuroscience Letters, Vol. 541 (April 2013): pg. 243-247. DOI. This article is (C) Elsevier and permission has been granted for this version to appear in e-Publications@Marquette. Elsevier does not grant permission for this article to be further copied/distributed or hosted elsewhere without the express permission from Elsevier. 
hand dominance at a given workspace. Alternatively, such a conflict may lead to incomplete development of a neural representation associated with a given visuomotor condition. If the former explanation is correct, a conflict between visual and motor workspaces should not interfere with generalization of visuomotor adaptation across movement conditions in which the same arm is used. However, if the latter explanation is correct, the conflict should also disturb within-arm generalizations. The current study demonstrated limited transfer across movement conditions within the same arm under the conditions in which visual and motor workspaces were separated, which supports the latter view that a conflict between visual and proprioceptive information in terms of workspace locations disrupts the development of a neural representation associated with a novel visuomotor condition.

When one adapts to a novel sensorimotor condition, two types of internal models may be developed, one based on visual information and the other based on proprioceptive information, which combine to guide reaching performance [6]. This is in agreement with the idea that the planning of reaches to visual and proprioceptive targets may involve distinct planning mechanisms [10] and [12]. Based on these ideas, we speculate that separating visual and motor workspaces caused the relationship between the two types of sensory information and the two types of internal models to depend on the nature of a given workspace. That is, when subjects viewed their performance in a midline workspace while physically performing the adaptation task in a lateral workspace, an internal model was formed in relation to the midline workspace, which primarily relied on the visual information regarding the subjects' performance, and another model in relation to the motor workspace, which primarily relied on their proprioceptive information. In this condition, combining the two internal models would create a serious computational problem because the visual and proprioceptive estimates of limb state represented in one model would not match with those represented in the other model. This would disrupt the development of an overall neural representation that underlies adaptation to a novel visuomotor transform, which in turn would negatively affect generalization of that adaptation not only across the limbs, but also across different workspace conditions within the same limb.

Neuroscience Letters, Vol. 541 (April 2013): pg. 243-247. DOI. This article is (C) Elsevier and permission has been granted for this version to appear in e-Publications@Marquette. Elsevier does not grant permission for this article to be further copied/distributed or hosted elsewhere without the express permission from Elsevier. 
In this study, we also compared the course of adaptation between two subject groups in which visuomotor adaptation acquired under the dissociation condition was generalized to an association condition in which either the visual or the motor workspace was the same as that in the dissociation condition (AssocM and AssocL, respectively). Our results indicated no difference between the two subjects groups in terms of the intercept or the slope of regression equations. This suggests that the vision-based and the proprioceptionbased models contribute equally to the development of the overall representation underlying visuomotor adaptation. Considering that visual and proprioceptive information may play differential roles in the planning and execution of reaching movement [9], [10], [11] and [12], however, additional research is needed to better understand the roles of these two internal models in sensorimotor adaptation and its generalization across movement conditions.

\section{Highlights}

- Separating visual and motor workspaces disturbs transfer of visuomotor adaptation.

- Internal models are formed based on sensory information associated with workspaces.

- A conflict between workspaces disrupts neural representation underlying adaptation.

\section{Footnotes}

Publisher's Disclaimer: This is a PDF file of an unedited manuscript that has been accepted for publication. As a service to our customers we are providing this early version of the manuscript. The manuscript will undergo copyediting, typesetting, and review of the resulting proof before it is published in its final citable form. Please note that during the production process errors may be discovered which could affect the content, and all legal disclaimers that apply to the journal pertain.

\section{References}

1. Bagesteiro LB, Sainburg RL. Handedness: dominant arm advantages in control of limb dynamics. J Neurophysiol. 2002;88:2408-2421.

Neuroscience Letters, Vol. 541 (April 2013): pg. 243-247. DOI. This article is (c) Elsevier and permission has been granted for this version to appear in e-Publications@Marquette. Elsevier does not grant permission for this article to be further copied/distributed or hosted elsewhere without the express permission from Elsevier 
NOT THE PUBLISHED VERSION; this is the author's final, peer-reviewed manuscript. The published version may be accessed by following the link in the citation at the bottom of the page.

2. Bagesteiro LB, Sainburg RL. Nondominant arm advantages in load compensation during rapid elbow joint movements. J Neurophysiol. 2003;90:1503-1513.

3. Franz E, Ivry R, Gazzaniga MS. Dissociation of spatial and temporal coupling in the bimanual movements of callosotomy patients. Psychol Sci. 1996;7:306-310.

4. Heuer $\mathrm{H}$, Hegele M. Generalization of implicit and explicit adjustments to visuomotor rotations across the workspace in younger and older adults. J Neurophysiol. 2011;106:2078-85.

5. Holtzman JD, Gazzaniga MS. Dual task interactions due exclusively to limits in processing resources. Science. 1982;218:1325-1327.

6. Hwang EJ, Smith MA, Shadmehr R. Dissociable effects of the implicit and explicit memory systems on learning control of reaching. Exp Brain Res. 2006;173:425-437.

7. Krakauer JW, Pine ZM, Ghilardi MF, Ghez C. Learning of visuomotor transformations for vectorial planning of reaching trajectories. J Neurosci. 2000;20:8916-8924.

8. Sainburg RL, Wang J. Interlimb transfer of visuomotor rotations: independence of direction and final position information. Exp Brain Res. 2002;145:437-447.

9. Sainburg RL, Lateiner JE, Latash ML, Bagesteiro LB. Effects of altering initial position on movement direction and extent. J Neurophysiol. 2003;89:401-415.

10. Sarlegna FR, Sainburg RL. The effect of target modality on visual and proprioceptive contributions to the control of movement distance. Exp Brain Res. 2007;176:267-280.

11. Sober SJ, Sabes PN. Multisensory integration during motor planning. J Neurosci. 2003;23:6982-6992.

12. Sober SJ, Sabes PN. Flexible strategies for sensory integration during motor planning. Nat Neurosci. 2005;8:490-497.

13. Thomas $M$, Bock O. Concurrent adaptation to four different visual rotations. Exp Brain Res. 2012;221:85-91.

14. Vetter P, Goodbody SJ, Wolpert DM. Evidence for an eye-centered spherical representation of the visuomotor map. J Neurophysiol. 1999;81:935-939.

Neuroscience Letters, Vol. 541 (April 2013): pg. 243-247. DOI. This article is (C Elsevier and permission has been granted for this version to appear in e-Publications@Marquette. Elsevier does not grant permission for this article to be further copied/distributed or hosted elsewhere without the express permission from Elsevier. 
NOT THE PUBLISHED VERSION; this is the author's final, peer-reviewed manuscript. The published version may be accessed by following the link in the citation at the bottom of the page.

15. Wang J. A dissociation between visual and motor workspace inhibits generalization of visuomotor adaptation across the limbs. Exp Brain Res. 2008;187:483-490.

16. Wang J, Sainburg RL. Adaptation to visuomotor rotations remaps movement vectors, not final positions. J Neurosci. 2005;25:40244030 .

17. Wang J, Sainburg RL. The symmetry of interlimb transferdepends on workspace locations. Exp Brain Res. 2006;170:464-471.

18. Woolley DG, Tresilian JR, Carson RG, Riek S. Dual adaptation to two opposing visuomotor rotations when each is associated with different regions of workspace. Exp Brain Res. 2007;179:155-165.

19. Woolley DG, de Rugy A, Carson RG, Riek S. Visual target separation determines the extent of generalisation between opposing visuomotor rotations. Exp Brain Res. 2011;212:213-24.

\section{About the Authors}

Jinsung Wang Department of Kinesiology, 492 Enderis Hall, The University of Wisconsin, Milwaukee, WI 53201, USA. Tel.: +1414229 3226; fax: +14142292619.

Email: wang34@uwm.edu

Neuroscience Letters, Vol. 541 (April 2013): pg. 243-247. DOI. This article is (C) Elsevier and permission has been granted for this version to appear in e-Publications@Marquette. Elsevier does not grant permission for this article to be further copied/distributed or hosted elsewhere without the express permission from Elsevier. 